\title{
Effect of Different Remineralizing Agents on White Spot Lesions
}

\author{
Ebaa Alagha $^{1 *}$, Amira Mohammad Samy ${ }^{2}$ \\ ${ }^{1}$ Assistant Professor of Operative Dentistry, Department of Restorative Dentistry, Al-Farabi Private Colleges, Jeddah, Saudi \\ Arabia; ${ }^{2}$ Lecturer of Operative Dentistry, School of Oral and Dental Medicine, Badr University, Badr City, Egypt
}

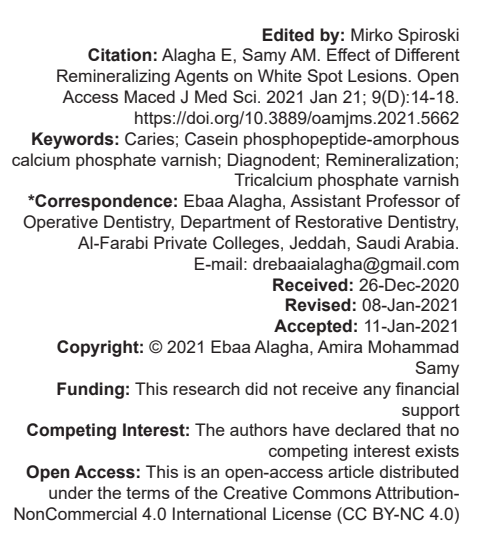

Background

Dental caries is one of the major dental challenging problems maybe more prominent than other infectious diseases such as hypertension and heart infections [1]. It is easily detectable and reversible at an early stage. Once the incipient lesion proceeds to cavitation, the condition becomes irreversible. That is why it is important to prevent the progression of caries at early stages, instead of developing treatment procedures to treat its advanced stages [2]. White spot lesions are the earliest macroscopic evidence of enamel caries. Early stages of tooth demineralization are reversed by saliva, which contains fluoride, calcium, and phosphate ions, buffering agents, and other substances [3]. After orthodontic treatment, studies proved that white spot lesions can develop within 1 month and it varies from $2 \%$ to $96 \%$ [4] and fluoride is the most commonly agent used to treat these white spot lesions such as topical fluorides [5] but the major inadequacy of the toothpastes, mouth rinses, and topical applications is their limited ability to remineralize enamel by the low concentration of calcium and phosphate ions available in saliva [6]. New remineralization materials have been launched out, among which the well-known is the use of fluoride [7]. A few of them are bioactive glass, casein phosphopeptide-amorphous calcium phosphate (CPP-ACP), and hydroxyapatite with fluoride [8]. Fluoride varnish is a standard remineralizing agent created to drag out the contact time between fluoride and the tooth surface acting as a moderate discharging store of fluoride. Including calcium phosphate salts, such as tricalcium phosphate (TCP) to the varnish, may improve the mineralization of dentin. To upgrade the impact of the varnish, calcium and phosphate have been included [9]. Remineralization and anticariogenic mechanism of CPP-ACP includes the joining of nanocomplexes into dental plaque and onto the tooth surface, which in this manner acts as a calcium and phosphate reservoir. Several methods have been used to assess the degree of remineralization, including DIAGNOdent, quantitative light-induced fluorescence, scanning electron microscopy, polarized light microscope, X-ray spectrophotometer, standard photography, microcomputed tomography, and transverse microradiography [10]. Diagnodent is a laser device which measures fluorescence, early demineralization with good to excellent sensitivity and improves the demonstrative precision of location of non-cavitated carious lesions [1]. This study will use Diagnodent to evaluate the impact of two remineralizing agents containing CPP-ACP and TCP on white spot lesions. 


\section{Materials and Methods}

A total of 90 freshly extracted upper premolars were used in this study which were extracted for orthodontic purposes after obtaining written informed consent from the patients. Ethics approval was obtained from the Research Ethical Committee, Al-Farabi Private Colleges in Jeddah-KSA (Approval No20-03/6). The sample size calculations were performed using $\mathrm{G}$ Power v3.1.3 software (University of Düsseldorf, Düsseldorf, Germany). A power analysis showed that a sample size of 30 specimens per group was found to meet the constraints of $\alpha=0.05$ and power $=0.90$. Teeth were washed under water and scaled using a sharp hand scaler to remove any plaque, calculus, or softtissue remnants then stored in normal saline at room temperature (approximate $25^{\circ} \mathrm{C}$ ) until used. Then, teeth sectioned vertically, mesiodistally into buccal and lingual haves by cutting machine (E96, USA) using a diamond disk (EDENTA Golden S.A.W, Swiss made). The buccal parts of the teeth were dried and painted with two layers of nail varnish uncovering a window of $2 \mathrm{~mm} \times 2 \mathrm{~mm}$ on the center of the buccal surface of the teeth and left to dry. The teeth were divided into three groups according to the material used (30 each): Group A: Control group: Samples in artificial saliva, Group B: Varnish containing CPP-ACP (MI Varnish GC, USA), and Group C: Varnish containing TCP (3M, ESPE, M Vanish $5 \%$ sodium fluoride white varnish with TCP, USA). Diagnodent (Kavo, Biberach, Germany) was used to examine if there are any surface changes on the labial window. Only samples with 3 and 7 values on the digital display were used in this study as Diagnodent score between 3 and 7 indicates normal enamel [11]. The baseline values of all groups were recorded. Samples were immersed in three glass containers with $12 \mathrm{ml}$ of demineralizing solution according to each group for 9 days at room temperature (approximate $25^{\circ} \mathrm{C}$ ) [12] to induce artificial caries-like lesion. The demineralizing solution had the following composition: $\mathrm{CaCl}_{2}=2.2 \mathrm{mM}, \mathrm{NaH}_{2} \mathrm{PO}_{4}=2.2 \mathrm{mM}$, lactic acid $=0.05 \mathrm{M}$, and fluoride $=0.2 \mathrm{pp}$, adjusted with $50 \%$ $\mathrm{NaOH}$ to a pH 4.5 [13]. The $\mathrm{pH}$ of the demineralizing solution was checked during and after preparation of solution using digital $\mathrm{pH}$ meter. The solution was replaced every 3 days [14]. Then, the samples washed with deionized water and dried with air syringe. Group A: Control group teeth were placed in artificial saliva to prevent dehydration [2]. Group B: Teeth were coated with varnish containing CPP-ACP using microbrush for 4 min every $24 \mathrm{~h}$ and placed back in the artificial saliva solution without rinsing for 7 days. Group C: Teeth were coated with varnish containing TCP in the same way as Group B. The composition of artificial saliva contains $0.65 \mathrm{~g} / \mathrm{l}$ potassium chloride, $0.058 \mathrm{~g} / \mathrm{l}$ magnesium chloride, $0.165 \mathrm{~g} / \mathrm{l}$ calcium chloride, $0.804 \mathrm{~g} / \mathrm{l}$ dipotassium hydrogen phosphate, $0.365 \mathrm{~g} / \mathrm{l}$ potassium dihydrogen phosphate, $2 \mathrm{~g} / \mathrm{l}$ sodium carboxymethyl cellulose, and distilled water [15]. Diagnodent with probe tip $B$ was used to measure the values. The device was calibrated against a porcelain standard before reading and after testing each five teeth. The probe tip B was kept perpendicular to the tooth surface. The values were recorded, tabulated, and statistically analyzed using one-way ANOVA and Tukey's multiple comparison tests. All data were analyzed by SPSS software (SPSS 16.0, Chicago, IL, USA).

\section{Results}

Statistically significant difference was present in the mean values between the tested groups. CPPACP group (14.73) recorded higher mean value at demineralization when compared to TCP group (13.87). Statistically significant difference $(p<0.0001)$ was present between the baseline and the demineralization values. CPP-ACP group (2.67) presented higher remineralization results when compared to TCP group (2.07). t-test proved a significant difference between the tested groups $(p=0.019)$ (Table 1$)$.

Table 1: Comparison between two varnishes

\begin{tabular}{|c|c|c|c|c|}
\hline Variables & CPP-ACP & TCP & Total & $\mathrm{p}$-value \\
\hline Control (A) & $3.60 \pm 0.507$ & $3.40 \pm 0.737$ & $3.50 \pm 0.630$ & 0.394 \\
\hline After demineralization (B) & $14.73 \pm 0.884$ & $13.87 \pm 0.516$ & $14.30 \pm 0.837$ & $0.003^{*}$ \\
\hline After remineralization (C) & $2.67 \pm 0.817$ & $2.07 \pm 0.458$ & $2.37 \pm 0.718$ & $0.019^{\star}$ \\
\hline
\end{tabular}
phosphate.

\section{Discussion}

Diagnodent shows higher sensitivity and accuracy in enamel caries detection when compared with other conventional methods (visual and tactile examination and bitewing radiographs) [16]. It was developed by Lussi in 2004, a value of 5-25 indicates early lesions, 26-35 indicates early dentin caries, and over 35 indicates deep dentin caries but it is most important disadvantage that it can give false positive results in the presence of plaque and calculus, or softtissue remnants, therefore, the teeth were cleaned properly in this study [17]. Two commercially available remineralizing agents were used: Varnish containing CPP-ACP (MI Varnish, GC, USA) and varnish containing TCP (3M, ESPE, M Varnish TM 5\% sodium fluoride white varnish with TCP, USA). CPP-ACP is a bioactive agent with a base of milk products able to bind calcium and phosphate ions to stabilize calcium phosphate in solution and to increase the level of calcium phosphate in dental plaque [18]. It was used for the $1^{\text {st }}$ time in 2009 to treat white spot lesions [19] and many studies proved that it is positive effect in prevention of secondary caries. Karlinsey et al. [20] showed that adding calcium phosphate salts, 
such as tricalcium phosphate (TCP), to the varnish may improve the mineralization of bovine dentin, but few studies have addressed the effect of tricalcium phosphate on teeth. These two varnishes have different mechanism of action, but they both proved enhancement in the remineralization process. Remineralization is defined as the redeposition of lost minerals in enamel, and this term is used as a synonymous of repair or rehardening of enamel [21]. CCP-ACP is a source of the calcium and phosphate that inhibit demineralization and/or enhances remineralization. Prevention of demineralization is possible by the presence of casein which can buffer plaque acid either straightforwardly or through bacterial catabolism. It has the ability to discharge amino acids which accept protons and act as buffers [8]. Newly remineralization and anticariogenic mechanism of CPPACP includes the incorporation of nanocomplexes in the dental plaque and on the tooth surface and acts as a calcium and phosphate store, in addition to its high safety level [22]. The synergistic effect of CPP-ACP and fluoride in reducing the white spot lesions is related to the formation of CPP-stabilized amorphous calcium fluoride phosphate which increased the concentration of bioavailable calcium and phosphate particles [23]. Another studies proved that CPP reduces the adherence and functioning of cariogenic streptococcus bacteria in the oral cavity [24]. In this study, statistically significant difference presented in the mean values between the tested groups. The mean value showed high demineralization results for CPP-ACP group (14.73) when compared to TCP group (13.87). Statistically significant difference $(p<0.0001)$ was also presented between the tested groups at the baseline and the demineralization value. Best results in remineralization were observed in CPP-ACP group (2.67) when compared to TCP group (2.07). Significant difference was observed between the tested groups $(p=0.019)$. Kamath et al. [25], in their study on the initial carious lesions, evaluated the effect of different remineralizing materials includes tricalcium phosphate TCP, CPP-ACFP, and nanohydroxyapatite and all these materials had a remineralization effect. TCP significant remineralizing effect is clarified by the high levels of calcium and phosphorus ions in addition to the presence of fluoride ions in the saliva which is considered as an appropriate remineralization solution which encourages the remineralization of the initial carious lesions. The results agreed with Bajaj et al. [26] who treated initial carious lesions with functional TCP milled with sodium lauryl sulfate. Enamel remineralization of different calcium-phosphate and fluoride delivery systems was assessed with Vyavhare et al. [27] who compared the remineralization potential of fluoride, nanohydroxyapatite, and CPP-ACP and they stated that tested materials had high remineralization potential of fluoride. Furthermore, Ebrahimi et al. [28] agreed with the results of multiple studies who proved significant reduction of white spot lesions after the use of products containing CPP-ACP or CPP-ACPF. The results of this study agreed with Damyanova et al. [29] who used Clinpro white varnish and TCP and stated that it is effective lessening demineralization within the subsurface layer and in improving the remineralization of surface and subsurface enamel layer. Majithia et al. [30] observed that varnish with CPPACP with fluoride (MI Varnish) had better results in remineralization when compared to the other materials. Cochrane et al. [31] observed a fast discharge of calcium and inorganic phosphate particles under neutral condition which is reliable with the bioavailable nature of CPP-ACP contained within the varnish and that was related to high water solubility of CPP-ACP. Savas et al. [32] recommended the use of CPP-ACP containing fluoride varnish (MI Varnish) in the dental clinics as it improves the remineralization of incipient carious lesions after a single application. On the other hand, multiple remineralization researches done by Karabekiroglu et al. [33] and Robertson et al. [34] stated that the efficiency of casein phosphopeptide amorphous calcium phosphate is unreliable in reducing the white spot lesions. This was explained by El zankalouny et al. [15] who stated that the impact of CPP-ACP localizes the amorphous calcium phosphate by CPP onto the tooth surface, which makes a hypersaturation state regarding the tooth mineral. In another study, it was proved that CPP-ACP alone without the presence of fluoride could not prompt the formation of fluorapatite in the deep white spot lesions [35]. However, within the limitation of this study, as Diagnodent is not as precise as a scanning electron microscopy, further clinical trials are recommended to evaluate the effect of these agents and to speed up the repair process of the white spot lesions for better esthetic.

\section{Conclusion}

CPP-ACP containing varnish had higher remineralizing effect when compared to TCP containing varnish.

\section{Clinical significance}

Recently, the focus of restorative dentistry has been directed toward a conservative approach. Prevention and non-restorative treatment of initial enamel caries is the main concern. Remineralization procedures are the most preferred way of regeneration of lost tooth structure.

\section{References}

1. Yazicioğlu O, Yaman B, Güler A, Koray F. Quantitative evaluation of the enamel caries which were treated with 
casein phosphopeptideamorphous calcium fluoride phosphate. Niger J Clin Pract. 2017;20(6):686-92. https://doi. org/10.4103/1119-3077.180073

\section{PMid:28656922}

2. Ragendran R, Kunjusankaran R, Sandhya R, Anilkumar A Santhosh R, Patil S. Comparative evaluation of remineralizing potential of a paste containing bioactive glass and a topical cream containing casein phosphopeptide-amorphous calcium phosphate: An in vitro study. Pesq Bras Odontol Clin Int. 2019;19: 1-10. https://doi.org/10.4034/pboci.2019.191.61

3. Varma V, Hegde K, Bhat S, Sargod S, Rao H. Comparative evaluation of remineralization potential of two varnishes containing CPP-ACP and tricalcium phosphate: An in vitro study. Int J Clin Pediatr Dent. 2019;12:233-6. https://doi.org/10.5005/ jp-journals-10005-1629

\section{PMid:31708621}

4. Dai Z, Liu M, Ma Y, Cao L, Xu H, Zhang K, et al. Effects of fluoride and calcium phosphate materials on remineralization of mild and severe white spot lesions. BioMed Res Int. 2019;16:1271523. https://doi.org/10.1155/2019/1271523

5. Singh S, Singh1 S, Goyal A, Utreja A, Jena A. Effects of various remineralizing agents on the outcome of post-orthodontic white spot lesions (WSLs): A clinical trial. Prog Orthod. 2016;17(1):17-25. https://doi.org/10.1186/s40510-016-0138-9 PMid:27480987

6. Babu KG, Subramaniam P, Teleti S. Remineralization potential of varnish containing casein phosphopeptides-amorphous calcium phosphate with fluoride and varnish containing only fluoride: A comparative study. Saudi J Oral Sci. 2018;5(1):35. https://doi.org/10.4103/sjos.sjoralsci_44_17

7. Jayarajan J, Janardhanam P, Jayakumar P, Deepika. Efficacy of CPPACP and CPPACPF on enamel remineralization an in vitro study using scanning electron microscope and DIAGNOdent. Ind J Dent Res. 2011;22(1):7782. https://doi. org/10.4103/0970-9290.80001

PMid:21525682

8. Rajan R, Krishnan R, Bhaskaran B, Kumar S. A Polarized light microscopic study to comparatively evaluate four remineralizing agents on enamel viz CPP-ACPF, ReminPro, SHY-NM and colgate strong teeth. Int J Clin Pediatr Dent. 2015;8(1):42-7. https://doi.org/10.5005/jp-journals-10005-1281

PMid:26124580

9. Rirattanapong P, Vongsavan K, Saengsirinavin C, Pornmahala T. Effect of fluoride varnishes containing tri-calcium phosphate sources on remineralization of initial primary enamel lesions. Southeast Asian J Trop Med Public Health. 2014;45(2):499-504. PMid:24968692

10. Tahmasbi S, Mousavi S, Behroozibakhsh M, Badiee M. Prevention of white spot lesions using three remineralizing agents: An in vitro comparative study. J Dent Res Dent Clin Dent Prospects. 2019;13(1):36-42. https://doi.org/10.15171/ joddd.2019.006

PMid:31217917

11. Patil N, Choudhari S, Kulkarni S, Joshi S. Comparative evaluation of remineralizing potential of three agents on artificially demineralized human enamel: An in vitro study. J Conserv Dent. 2013;16(2):116-20. https://doi.org/10.4103/0972-0707.108185 PMid:23716961

12. Tahmasbi S, Adhami M, Valian A, Hamedi R. Effect of three different remineralizing agents on white spot lesions: An in vitro comparative study. J Islam Dent Assoc Iran 2016;28(3):98-103. https://doi.org/10.30699/jidai.29.3.98

13. Yadav J, Desai H, Patel K, Patel N, lyengar S. A comparative quantitative and qualitative assessment in orthodontic treatment of white spot lesion treated with 3 different commercially available materials in vitro study. J Clin Exp Dent. 2019;11(9):e776-82. https://doi.org/10.4317/jced.56044

PMid:31636868

14. Bahrololoomi Z, Musavi S, Kabudan M. In vitro evaluation of the efficacy of laser fluorescence (DIAGNOdent) to detect demineralization and remineralization of smooth enamel lesions. J Conserv Dent. 2013;16(4):362-6. https://doi. org/10.4103/0972-0707.114360

PMid:23956542

15. El-zankalouny S, Abd El Fattah W, El-Shabrawy S. Penetration depth and enamel microhardness of resin infiltrant and traditional techniques for treatment of artificaial enamel lesions. Alexandria Dent J. 2016;41:20-5. https://doi.org/10.21608/ adjalexu.2016.59167

16. Goel A, Chawla HS, Gauba K, Goyal A. Comparison of validity of DIAGNOdent with conventional methods for detection of occlusal caries in primary molars using the histological gold standard: An in vivo study. J Indian Soc Pedod Prev Dent. 2009;27(4):227-34. https://doi.org/10.4103/0970-4388.57658 PMid:19915274

17. Lussi A, Megert B, Longbottom C, Reich E, Francescut P. Clinical performance of a laser fluorescence device for detection of occlusal caries lesions. Eur J Oral Sci. 2001;109(1):14-9. https://doi.org/10.1034/j.1600-0722.2001.109001014.x PMid:11330928

18. Reema S, Lahiri P, Roy S. Review of casein phosphopeptidesamorphous calcium phosphate. Chin $J$ Dent Res. 2014;17(1):7-14.

\section{PMid:25028684}

19. Bailey D, Adams G, Tsao C, Hyslop A, Escobar K, Manton DJ et al. Regression of post-orthodontic lesions by a remineralizing cream. J Dent Res. 2009;88(12):1148-53. https://doi. org/10.1177/0022034509347168

PMid:19887683

20. Karlinsey R, Mackey A, Stookey G, Pfarrer A. In vitro assessments of experimental $\mathrm{NaF}$ dentifrices containing a prospective calcium phosphate technology. Am J Dent. 2009;22(3):180-4.

PMid:19650601

21. Cury J, Tenuta L. Enamel remineralization: Controlling the caries disease or treating early caries lesions? Braz Oral Res. 2009;23(1):23-30. https://doi.org/10.1590/ s1806-83242009000500005 PMid:19838555

22. Ma $X$, Lin $X$, Zhong $T$, Xie F. Evaluation of the efficacy of casein phosphopeptide-amorphous calcium phosphate on remineralization of white spot lesions in vitro and clinical research: A systematic review and meta-analysis. BMC Oral Health. 2019;19(1):295. https://doi.org/10.21203/rs.2.13495/v3 PMid:31888600

23. Cross K, Huq N, Stanton D, Sum M, Reynolds E. NMR studies of a novel calcium, phosphate and fluoride delivery vehicle alphs (S1)-casein (59-79) by stabilized amorphous calcium fluoride phosphate nanocomplexes. Biomaterials. 2004;25(20):5061-9. https://doi.org/10.1016/j.biomaterials.2004.01.045 PMid:15109869

24. Temel S, Kaya B. Diagnosis, prevention and treatment of white spot lesions related to orthodontics. Int J Oral Dent Health. 2019;5(2):1-7.

25. Kamath $P$, Nayak R, Kamath S, Pai D. A comparative evaluation of the remineralization potential of three commercially available remineralizing agents on white spot lesions in primary teeth: An in vitro study. J Indian Soc Pedod Prev Dent. 2017;35(3):22937. https://doi.org/10.4103/jisppd.jisppd_242_16 PMid:28762349

26. Bajaj A, Poornima P, Praveen S, Nagaveni N, Roopa K, 
Neena I, et al. Comparison of CPP-ACP, Tri-Calcium phosphate and hydroxyapatite on remineralization of artificial caries like lesions on primary enamel an in vitro study. J Clin Pediatr Dent. 2016;40(5):404-9. https://doi.org/10.17796/1053-4628-40.5.404 PMid:27617382

27. Vyavhare S, Sharma D, Kulkarni V. Effect of three different pastes on remineralization of initial enamel lesion: An in vitro study. J Clin Pediatr Dent. 2015;39(2):149-60. https://doi. org/10.17796/jcpd.39.2.yn2r54nw24I03741

PMid:25823485

28. Ebrahimi M, Mehrabkhani M, Ahrari F, Parisay I, Jahantigh M. The effects of three remineralizing agents on regression of white spot lesions in children: A two-week, single-blind, randomized clinical trial. J Clin Exp Dent. 2017;9(5):641-8. https://doi. org/10.4317/jced.53582

PMid:28512540

29. Damyanova D. In vitro study of the effects of fluoridereleasing dental materials on re-mineralization of deciduous teeth. IOSR J Dent Med Sci 2016;15(7):98-101. https://doi. org/10.9790/0853-1507898101

30. Majithia U, Venkataraghavan K, Choudhary P, Trivedi K, Shah S, Virda M. Comparative evaluation of application of different fluoride varnishes on artificial early enamel lesion: An in vitro study. Indian J Dent Res 2016;27(5):521-7. https://doi. org/10.4103/0970-9290.195642
PMid:27966511

31. Cochrane N, Shen $P$, Yuan $Y$, Reynolds $E$. Ion release from calcium and fluoride containing dental varnishes. Aust Dent $\mathrm{J}$. 2014;59(1):100-5. https://doi.org/10.1111/adj.12144 PMid:24494654

32. Savas S, Kavrik F, Kucukyilmaz E. Evaluation of the remineralization capacity of CPPACP containing fluoride varnish by different quantitative methods. JAppl Oral Sci. 2016;24(3):198203. https://doi.org/10.1590/1678-775720150583 PMid:27383699

33. Karabekiroğlu S, Ünlü N, Küçükyilmaz E, Şener S, Botsali MS, Malkoç S. Treatment of post-orthodontic white spot lesions with CPP-ACP paste: A three year follow up study. Dent Mat J. 2017;36(6):791-7. https://doi.org/10.4012/dmj.2016-228 PMid:28835597

34. Robertson M, Kau C, English J, Lee R, Powers J, Nguyen J. MI Paste Plus to prevent demineralization in orthodontic patients: A prospective randomized controlled trial. Am J Orthop Dentofacial Orthop. 2011;140(5):660-8. https://doi. org/10.1016/j.ajodo.2010.10.025

35. Reynolds E, Cai F, Cochrane N, Shen P, Walker G, Morgan M. Fluoride, and casein phosphopeptide- amorphous calcium phosphate. J Dent Res. 2008;87(4):344-8. https://doi. org/10.1177/154405910808700420

PMid:18362316 